\title{
Impact of Microplastics on Aquatic Organisms and Human Health: A Review
}

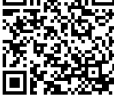

\author{
Sanjay Kumar ${ }^{1}$, Mridula Rajesh ${ }^{1}$, Rajesh $K^{2}{ }^{2}$, Suyani NK ${ }^{1}$ Ahamed Rasheeq A $^{1}$ and Pratiksha $\mathbf{K S}^{1}$ \\ ${ }^{1}$ Department of Fisheries Resources and Management, College of Fisheries, India
}

${ }^{2}$ ICAR-Central Marine Fisheries Research Institute, India

Submission: September 11, 2020; Published: October 19, 2020

*Corresponding author: Mridula Rajesh, Department of Fisheries Resources and Management, College of Fisheries, Mangaluru - 575002 , Karnataka, India

Abstract

Since the development of commercially viable plastic in the 1950s, plastics have become an increasingly important packaging option worldwide. Unfortunately, these materials are increasingly under environmental scrutiny. Larger plastic debris slowly degrades into small fragments with various sizes ranging from meter to micrometer due to changing environmental conditions. Microplastics are a complex class of heavily modified, synthetic organic particulates, which contaminate a wide range of environments. They are a cause for concern because their size range mimics the prey size ingested by the aquatic organisms and these ingested microplastics can be potentially transferred to the higher predators. Recent studies have confirmed the ingestion of microplastics in commercially important fishes, which is ultimately consumed by humans. Thus, massive efforts are required to investigate the distribution and abundance of microplastics in the ocean, and in considering strategies to reduce the problem. Research is urgently needed, especially regarding the potential exposure and associated human health risk to micro and nano-sized plastics.

Keywords: Aquatic organisms; Contamination; Human health; Microplastics; Plastics

\section{Introduction}

Plastics are synthetic organic polymers derived from the polymerization of monomers extracted from petroleum and other products. They are lightweight, inexpensive, and durable materials, which can easily be sculptured into a variety of products that retrieve use in an extensive application. Plastics have attained a crucial status in modern life and are now ubiquitous [1]. The squeezing of plastics was bound in 1839 with the discovery of vulcanized rubber and polystyrene. In Belgium, the first truly synthetic polymer, Bakelite, was produced in 1907. Extensive production of plastics began in 1940s and ever since it continued to expand. After 1950s, production of plastics has increased exponentially from 1.7 million tons to 360 million tons in 2018 [2] and it is the fastest growing urban waste accounting $60-80 \%$ of marine debris [3].

\section{Plastics - It's Everywhere}

Plastics have been found virtually in all environments ranging from the arctic to deserts to household dust. They are mainly introduced into the environment through ineffective waste management practices. It can be dispersed in the environment through atmospheric transport (wind) as well as through hydraulic systems (water flow). They can be carried into streams, rivers, wetlands and oceans (aquatic ecosystems) by wind as well as flowing water such as rain, snow melt that makes its way to streams, or via municipal or industrial water discharges (sewer water). Plastic pollution on land is concentrated in landfills, urban spaces and different agricultural lands that uses bio solids from municipal wastewater treatment plants. Majority of plastic polymers that find way to the environment are subjected to deterioration that is caused by various factors, including thermal oxidation, photo-oxidative degradation, hydrolysis and biodegradation (Table 1) [4]. However, the habitual plastics found in the marine environments do not biodegrade and primarily breakdown through photo-oxidative degradation.

Plastic compounds take up years to degrade into smaller fragments. Larger plastic debris slowly degrades into small fragments with various sizes ranging from meter to micrometer due to changing environmental conditions. This fragmented plastic with size smaller than $5 \mathrm{~mm}$ are termed as microplastics. According to GESAMP [5], microplastics (MPs) have been defined as small pieces of plastic less than five millimeters in size with no lower limit established. They are highly persistent in the 
aquatic ecosystem. These are not easily seen by the naked eye but are found in many areas, including lakes, rivers, oceans, sea ice, remote islands, Antarctic's, sediments and soil, as well as in the digestive systems, respiratory structures, and tissues of wildlife, including birds, mammals, reptiles, fish and shellfish [6].

Table 1: Feasible degradation course of synthetic polymers.

\begin{tabular}{|c|c|c|c|}
\hline Specification & Thermal / Thermo-oxidative degradation & Photo-degradation \\
\hline Vital ingredients & UV-light / high energy radiation & Heat and/or Oxygen & Above ambient temperature \\
\hline Heat obligation & None & Fast \\
\hline Degradation scale & Slow initiation, fast propagation & Moderate \\
\hline
\end{tabular}

\section{Categories of plastic debris}

Plastic debris can be expound and narrated in a variety of ways by shape, size, color, polymer type, origin (e.g. from the land, fishing-related or sewage-related debris) and original usage (e.g. packaging, rope). Based on origin, they are also categorized into primary and secondary microplastics depending on whether the particles were originally manufactured to be that size (primary) or whether they have resulted from the breakdown of macroplastics (secondary).

Four categories of plastics given by Barnes et al. [7] are as follows:

a) Macroplastics are large $(>20 \mathrm{~mm})$ plastic debris such as plastic bottles.

b) Mesoplastics are large plastic particles such as virgin resin pellets and are usually defined as $5-20 \mathrm{~mm}$ in range.

c) Microplastics are small plastic fragments typically less than $5 \mathrm{~mm}$ that are derived from the breakdown of macroplastics.

d) Nanoplastics are small microplastic particles ranging in size from $0.2-2 \mathrm{~mm}$.

The term mega-debris $(>100 \mathrm{~mm})$ is also used and can be applied to large debris items such as derelict fishing nets.

\section{Types of marine debris}

Marine debris is any manmade material including litter and fishing gear or rope that once lost or thrown into the marine environment. The most common materials that make up marine debris are plastics, glass, paper, metal, cloth, Styrofoam, rubber, wood, derelict fishing gear and abandoned and derelict vessels. High quantities of marine debris may be found on the shoreline close to urban areas because of high anthropogenic discards. United Nations of Environment Programme (UNEP) has included plastic (moulded, soft, foam, nets, ropes, buoys, monofilament line), fisheries related equipment, cigarette butts or lighters, metals (drink cans, bottle caps, pull tabs), glass (buoys, light globes, fluorescent globes, bottles), processed timber (including particle board), paper rubber and cloth in the list of marine debris.

The highest percentage of item of marine debris consists of cap, spoon, small sachets, syringe, paste tube, straw, pen assorted, plastic bits, bead, hair clips and the plastic and nylon ropes followed by thermocol and sponge [8]. The United Nations Joint Group of Experts on the Scientific Aspects of Marine Pollution (GESAMP) estimated that land-based sources are responsible for up to $80 \%$ of marine debris. Key components of land-based sources include litter, trash and debris from construction, ports and marinas, commercial and industrial facilities, and trash blown out of garbage containers, trucks, and landfills. Ocean-based sources, such as, overboard discharges from ships and discarded fishing gear, account for the other $20 \%$ [9].

\section{Composition of Microplastics}

Microplastics (MPs) have been defined as small fragments of plastic less than five millimeters in size with no lower extent entrenched [5]. The MPs present in the marine environment result from the fragmentation of larger plastic debris or may be introduced into the water and sediments already as micro- or nano-sized particles. Examples of microplastics are preproduction pellets and components of diverse products, such as fragments of fishing gear, packages and drink bottles, synthetic textiles, car tyres, paints, cosmetics and personal care products (e.g. facial cleaners, bath gels, toothpaste), and electronic equipment among others $[5,10,11]$. Consequently, microplastics encompass a very heterogeneous assemblage of particles that vary in size, shape, and chemical composition, among other properties [12,13]. Microplastics have been found worldwide, are highly persistent in the environment, and are therefore, accumulating in different marine ecosystems at increasing rates. MPs fragments are in a broad range of shapes and sizes:

a) Fragment - hard, jagged particle.

b) Fiber or line - thin or fibrous, straight plastic.

c) Pellet - hard, rounded, or spherical particle.

d) Film - thin plane of flimsy plastic.

e) Foam - lightweight, sponge-like plastic.

Differences in size and shape can affect the way particles move through the environment and may modify their potential for toxicity [14]. Ocean gyres, estuaries, and other coastal areas of heavily anthropogenic impacted regions are the ecosystems most polluted with MPs [15]. 


\section{Effects of microplastics on aquatic animals including fish}

There are numerous ways through which MPs and associated contaminants get incorporated into the aquatic biota. This includes filter feeding, suspension feeding, inhalation at air-water surface and consumption of prey exposed to MPs or through direct ingestion. Ingestion is believed to be a main MPs exposure route for several marine species. Ingestion of small plastic particles has been reported in more than six hundred and ninety marine species belonging to different trophic levels [16]. Aquatic animals including plankton passively ingest MPs due to their inability to differentiate MPs and food. The minute size, buoyancy and attractive color of MPs particles make them ideal candidates as food for fish.
In fish, after ingestion, the MPs may translocate across the gastrointestinal tract and gills and enter the circulatory system. The translocation may happen either through Tran's cellular uptake or by par cellular diffusion [14]. Through the blood, MPs reach different organs and muscles. Filter feeders filter larger volumes of water for food and in the process end up retaining MPs in their body. The chemical constituents (monomers and additives) of MPs contain endocrine disruptors which lead to change in fish behavior, gastrointestinal irritation, disruption of lipid metabolism, change in micro biome and can cause reproductive problems. However, presence of MPs in the aquatic environment and fish gut is an emerging concern that has been reported in different fishes from different locations of the world (Table 2).

Table 2: Occurrence of microplastics in different fish and shellfish.

\begin{tabular}{|c|c|c|c|c|}
\hline No. & Species & Common Name & Location & Reference \\
\hline 1 & Micromesistius poutassou & Blue whiting & English channel & Lusher et al. [17] \\
\hline 2 & Clupea harengus & Atlantic herring & North Sea and Baltic sea & Foekema et al. [18] \\
\hline 3 & Gadus morhua & Atlantic cod & Norwegian coast & Brate et al. [19] \\
\hline 4 & Sardinella longiceps & Indian oil sardine & Indian coast & Sulochanan et al. [8] \\
\hline 5 & Mytilus edulis & Blue mussel & North sea & Van Cauwenberghe \& Janssen [20] \\
\hline 6 & Crassostrea gigas & Pacific oyster & Local market of California, USA & Rochman et al. [21] \\
\hline 7 & Meretrix lusoria & Asian hard clam & Local fish market of China & Li et al. [22] \\
\hline 8 & Rastrelligerkanagurta & Indian mackerel & Local market of Eastern Indonesia & Rochman et al. [21] \\
\hline 9 & Decapterus macrosoma & Shortfin scad & Local market of California, USA & Rochman et al. [21] \\
\hline 10 & Sardina pilchardus & European pilchard & Mediterranean Sea & Guven et al. [23] \\
\hline 11 & Scomber japonicus & Chub mackerel & Mediterranean Sea & Guven et al. [23] \\
\hline 12 & Scomber scombrus & Atlantic mackerel & Baltic Sea & Rummel et al. [24] \\
\hline 13 & Engraulis japonicus & Japanese anchovy & Tokyo bay & Tanaka \& Takada [25] \\
\hline 14 & Penaeus semisulcatus & Green tiger prawn & Musa estuary, Persian Gulf & Abassi et al. [26] \\
\hline 15 & Cynoglossus thabbreviatus & Three lined tongue sole & Musa estuary, Persian Gulf & Abassi et al. [26] \\
\hline 16 & Dicentrarchus labrax & European bass & Mondego estuary, Portugal & Bessa et al. [27] \\
\hline 17 & Epinephelus areolatus & Areolate grouper & Saudi Arabian Red Sea coast & Baalkhuyur et al. [28] \\
\hline 18 & Mugil cephalus & Flathead grey mullet & Hong Kong coast & Cheung et al. [29] \\
\hline 19 & Mene maculata & Razor moonfish & Eastern Arabian Sea & Viswambharan et al. [30] \\
\hline
\end{tabular}

\section{Impact of plastic on marine environment}

Plastic pollution is one of the most widespread problems affecting the marine environment. It also threatens ocean health, food safety and quality, human health, coastal tourism, and contributes to climate change. Here are some of the major impacts of plastic pollution on the marine environment and associated flora and fauna.

\section{Marine environment}

Plastic debris is harmful to marine life including to protected species of birds, sharks, turtles, and marine mammals. Marine debris may cause injury or death through drowning, injury through entanglement and internal injuries, or starvation following ingestion.

a) Ghost fishing: Over 250 species of marine animals are impacted by entanglement such as turtles; penguins; albatrosses, petrels and shearwaters; shorebirds, gulls and auks; coastal birds other than seabirds; baleen whales, toothed whales and dolphins; earless or true seals, sea lions and fur seals; manatees and dugong; sea otters; fish and crustaceans. One of the greatest threats of 
entanglement to marine life and seabirds is derelict fishing gear, including monofilament line; trawl nets, and gill nets. Lost and free-floating fishing gear can continue to ghost fish for months and even years, ensnaring a wide range of species, particularly in areas adjacent to fishing grounds, along current convergence zones, and along shorelines where debris is deposited by currents and waves. Seabirds, turtles, whales, dolphins, dugongs, fish, crabs, crocodiles and numerous other species are killed and maimed through entanglement [31].

Once an animal is entangled, it may drown, and its ability to catch food or avoid predators is impaired, or incurs wounds from abrasive or cutting action of attached debris. Lost or abandoned fishing nets pose a particular great risk. These "ghost nets" continue to catch animals even if they sink or are lost on the seabed. Whales are also caught in their mouths or wrapped around their heads and tails. Debris entanglement can also have damaging effects on marine habitats such as coral reefs and sea grass resulting in the destruction from contact with derelict fishing gear.

b) Ingestion: Many animals, such as sea turtles, seabirds, and marine mammals have been known to ingest marine debris. The debris item may be mistaken for food and ingested as natural food or may have been ingested accidentally along with other food. Ingestion of marine debris may lead to reduction in the absorption of nutrients in the gut, reducing the amount of space for food in the gizzard and stomach, loss of nutrition, internal injury, intestinal blockage, starvation, and even death. Ingestion of MPs by marine organisms in the pelagic zone and sedimentary habitats has increased at concentrations of 150-2400 particles per $\mathrm{m}^{3}$. Due to small size and free-floating behavior of MPs in the water column makes it similar to plankton, which enable their consumption by aquatic biota at different trophic levels, thereby affecting the species at the organism-level and modify the population structure. The benthos is likely to be a sink for high density of MPs. Benthic suspension- and deposit- feeders are therefore likely to ingest sinking and sedimentary MPs.

c) Invasions of Alien species: Marine litter can serve as a means of transport for many species, with the potential risk to facilitate transport of exotic and invasive species altering the equilibrium in some areas such the open ocean or sandy seabed's. They would be first colonized by microorganisms and then, by macro biota, like mollusks, crustaceans, fishes, cnidaria and echinoderms. In case the debris floats, the organisms can be transported to other regions.

\section{Impacts on Economy}

Marine litter cause serious economic losses to various sectors and authorities. Among the most seriously affected are coastal communities (increased expenditures for beach cleaning, public health and waste disposal), tourism (loss of income, bad publicity), shipping (costs associated with fouled propellers, damaged engines, litter removal and waste management in harbors), fishing (reduced and lost catch, damaged nets and other fishing gear, fouled propellers, contamination), fish farming and coastal aquaculture (reduced seafood consumption).

\section{Impacts on climate change}

Oceans, which provide the largest natural carbon sink for greenhouse gases, plastic leaves a deadly legacy. It directly chokes and smothers a host of marine animals and habitats and can take hundreds of years to break down. Plastics, which is a petroleum product, contributes to the global warming. Sunlight and heat cause the plastic to release powerful greenhouse gases, leading to an alarming feedback loop. As our climate changes, the planet gets hotter, the plastic breaks down into more methane and ethylene, increasing the rate of climate change, and so continuing the cycle.

\section{Effects of microplastics on human health}

Human health risks are mainly attributed to the chemical additives on plastics and sorbed toxic compounds present on microplastics. Monomers of certain plastic polymers such as ethylene and ethylene terephthalate are not recognized as significant human health threat but styrene exhibits estrogen like activity [32] and vinyl chloride is a genetoxic and mutagenic agent [33]. Chemical additives added to plastics viz., phthalates, bisphenol-A, nonylphenols and flame retardants act as endocrine disruptors [34]. Toxic chemicals sorbed to microplastics and harmful pathogens attached to the microplastics have the potential to negatively affects human health.

When marine organisms ingest plastic debris, these contaminants enter their digestive systems, and overtime accumulate in the food web. The transfer of contaminants between marine species and humans through consumption of seafood has been identified as a health hazard. The pathway for ingestion of microplastics present in the marine aquatic environment by humans is depicted in Figure 1, which is a modification of Rao [35].

\section{Plan of action to mitigate microplastics in the aquatic environment}

a) The release of plastics to the aquatic environment needs to be drastically reduced. There is an urgent need to prohibit the use of microbeads in cosmetics towards reducing microplastics pollution.

b) Wastewater and drinking water treatments are highly efficient in getting rid of more than $90 \%$ of microplastics. Hence, wastewater treatment plants should be upgraded, and better waste management practices should be involved by creating recycling infrastructure so that the plastics could be eliminated from the water before they are released into the aquatic environment. 
c) Many interventions can be done by individuals to reduce microplastics entry in to the aquatic system. Perhaps the most important step lies in changing the way we think and behave. Hence, the product innovation for biodegradable alternatives to plastic polymers has to be strengthened and encouraged with the use of natural alternatives to additives used in plastic manufacture, edible cutlery, paper straws, biodegradable food wrappings, and edible food coatings. d) Upgradation of washing machine, which is the main reason for transfer of microplastic fibre particles from clothes, can prevent microplastic fibre particle from entering sewer.

e) Enhance public education through nationwide campaigns such as 'Beat Plastic Pollution' campaign of the United Nations and 'Green Good Deed' of Ministry of Environment, Forests and Climate Change, Government of India and campaigns to emphasize refuse, reuse and recycle plastics.

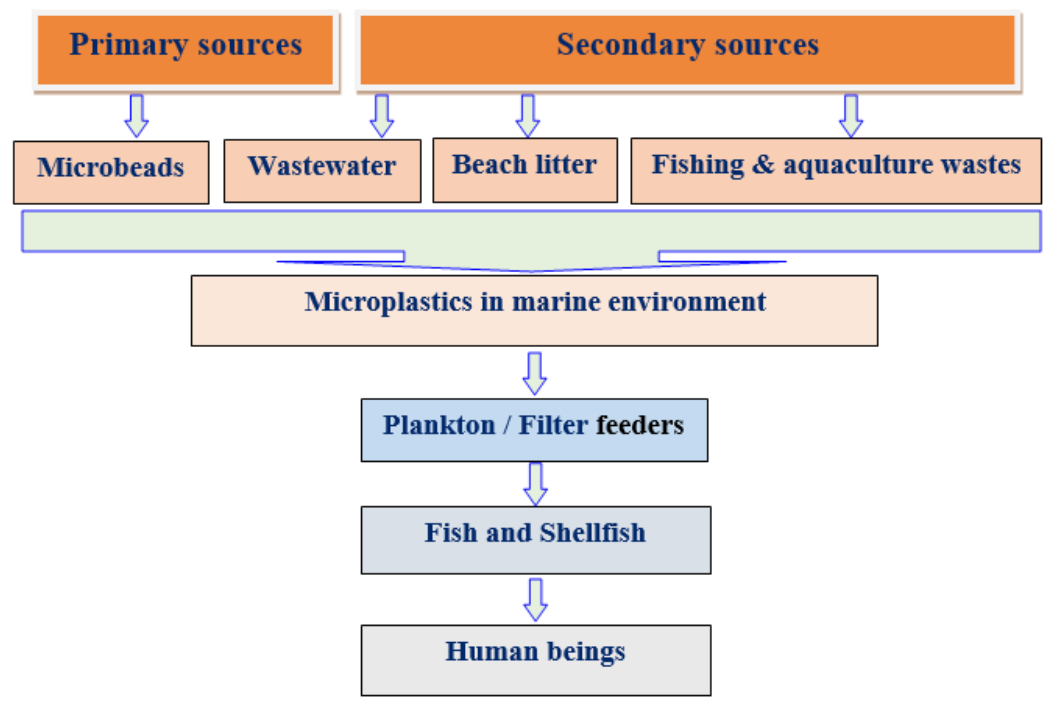

Figure 1: Route for ingestion of microplastics in marine environment.

\section{Conclusion}

The defilement of oceans by microplastics is of great concern due to its ecological as well as health impacts. They may compromise food security, food safety, and consequently human health. They have now taken place in all the corners of the world and in all the environments ranging from the arctic to deserts to household dust. As plastics takes more than 300 years to disintegrate in to micro and nano-plastics indicating the impact of plastic pollution on aquatic animal health and human health for years to come. The occurrence of microplastics in fish species used for human consumption is a global problem and we are vulnerable to microplastic exposure through the consumption of seafood and other human food items, as well as through other routes such as air. The impact of microplastic contamination of aquatic life on human health is currently unknown and is a potential area of research. Thus, there is a need of immediate priority and strong action plan to mitigate the microplastics pollution in the aquatic environment. Proper solid waste management programs and reduction in the use of plastics are required. Moreover, there is a need for coastal clean-up program and facilities to deposit nondegradable litter in public places.

\section{References}

1. Halden RU (2010) Plastics and health risks. Annual Review of Public Health 31: 179-194.

2. Plastics Europe (2019) Plastics - the facts 2019. In: Plastics Europe.

3. Moore CJ (2008) Synthetic polymers in the marine environment: a rapidly increasing, long-term threat. Environmental Research 108(2): 131-139.

4. Isangedighi IA, David GS, Obot OI (2018) Plastic Waste in the Aquatic Environment: Impacts and Management. Environment 2: 1-31.

5. GESAMP (2016) Sources, fate and effects of microplastics in the marine environment: part two of a global assessment. In: Kershaw PJ, Rochman CM (Eds.), IMO/FAO/UNESCO IOC/UNIDO/WMO/IAEA/UN/ UNEP/UNDP Joint Group of Experts on the Scientific Aspects of Marine Environmental Protection. Reports and Studies GESAMP, 93, p. 220.

6. Depledge MH, Galgani F, Panti C, Caliani I, Casini S, et al. (2013) Plastic litter in the sea. Marine Environmental Research 92: 279-281.

7. Barnes DK, Galgani F, Thompson RC, Barlaz M (2009) Accumulation and fragmentation of plastic debris in global environments. Philosophical Transactions of the Royal Society B 364(1526): 1985-1998.

8. Sulochanan B, Bhat GS, Lavanya S, Dineshbabu AP, Kaladharan PA (2014) preliminary assessment of ecosystem process and marine litter in the beaches of Mangalore. Indian Journal of Geo-Marine Sciences 43(9): 1-6. 
9. Sheavly SB (2005) Marine Debris - An Overview of a Critical Issue for Our Oceans. 6th Meeting of the UN Open-Ended Informal Consultative Processes on Oceans \& the Law of the Sea, New York, p. 7.

10. Fendall LS, Sewell MA (2009) Contributing to marine pollution by washing your face. Microplastics in facial cleansers. Marine Pollution Bulletin 58(8): 1225-1228.

11. Andrady AL (2011) Microplastics in the marine environment. Marine Pollution Bulletin 62(8): 1596-1605.

12. Hidalgo-Ruz V, Gutow L, Thompson RC, Thiel M (2012) Microplastics in the marine environment: a review of the methods used for identification and quantification. Environmental Science and Technology 46(6): 3060-3075

13. Andrady AL (2017) The plastic in microplastics: a review. Marine Pollution Bulletin 119(1): 12-22.

14. Wright SL, Kelly FJ (2017) Plastic and human health: a micro issue? Environmental Science and Technology 51(12): 6634-6647.

15. Frere L, Paul Pont I, Rinnert E, Petton S, Jaffré J, et al. (2017) Influence of environmental and anthropogenic factors on the composition, concentration and spatial distribution of microplastics: a case study of the Bay of Brest (Brittany, France). Environmental Pollution 225: 211-222.

16. Lavers JL, Bond AL (2017) Exceptional and rapid accumulation of anthropogenic debris on one of the world's most remote and pristine islands. Proceedings of the National Academy of Sciences of the United States of America 114(23): 6052-6055.

17. Lusher AL, Mchugh M, Thompson RC (2013) Occurrence of microplastics in the gastrointestinal tract of pelagic and demersal fish from the English Channel. Marine Pollution Bulletin 67(1-2): 94-99.

18. Foekema EM, De Gruijter C, Mergia MT, van Franeker JA, Murk AJ, et al. (2013) Plastic in North Sea fish. Environmental Science and Technology 47(15): 8818-8824.

19. Brate ILN, Eidsvoll DP, Steindal CC, Thomas KV (2016) Plastic ingestion by Atlantic cod (Gadus morhua) from the Norwegian coast. Marine Pollution Bulletin 112(1-2): 105-110.

20. Van Cauwenberghe L, Janssen CR (2014) Microplastics in bivalves cultured for human consumption. Environmental Pollution 193: 65-70.

21. Rochman CM, Tahir A, Williams SL, Baxa DV, Lam R, et al. (2015) Anthropogenic debris in seafood: plastic debris and fibers from textiles in fish and bivalves sold for human consumption. Scientific Reports 5: 14340.

22. Li J, Yang D, Li L, Jabeen K, Shi H (2015) Microplastics in commercial bivalves from China. Environmental Pollution 207: 190-195.
23. Guven O, Gokdag K, Jovanovic B, Kideys AE (2017) Microplastic litter composition of the Turkish territorial waters of the Mediterranean Sea, and its occurrence in the gastrointestinal tract of fish. Environmental Pollution 223: 286-294.

24. Rummel CD, Loder MGJ, Fricke NF, Lang T, Griebeler EM, et al. (2016) Plastic ingestion by pelagic and demersal fish from the North Sea and Baltic Sea. Marine Pollution Bulletin 102(1): 134-141.

25. Tanaka K, Takada H (2016) Microplastic fragments and microbeads in digestive tracts of planktivorous fish from urban coastal waters. Scientific Reports 6: 34351.

26. Abassi S, Soltani N, Keshavarzi B, Moore F, Turner A, et al. (2018) Microplastics in different tissues of fish and prawn from the Musa Estuary, Persian Gulf. Chemosphere 205: 80-87.

27. Bessa F, Barria P, Neto JM, Frias JPGL, Otero V, et al. (2018) Occurrence of microplastics in commercial fish from a natural estuarine environment. Marine Pollution Bulletin 128: 575-584.

28. Baalkhuyur FM, Dohaish JAB, Elhalwagy MEA, Alikunhi NM, Alsuwailem, et al. (2018) Microplastic in the gastrointestinal tract of fishes along the Saudi Arabian Red Sea coast. Marine Pollution Bulletin 131: 407-415.

29. Cheung LTO, Lui CY, Fok L (2018) Microplastic contamination of wild and captive flathead Grey mullet (Mugil cephalus). International Journal of Environmental Research and Public Health 15(4): 597.

30. Viswambharan D, Rohit P, Sasikumar G, Thomas S, Joshi KK, et al. (2019) Occurrence and abundance of plastic particles in razor moonfish along the eastern Arabian Sea. Journal of the Marine Biological Association of India 61(2): 27-33.

31. Hardesty BD, Wilcox C, Lawson TJ, Lansdell M, van der Velde T (2014) Understanding the effects of marine debris on wildlife. A final report to Earth watch Australia, p. 365.

32. Yang CZ, Yaniger SI, Jordan VC, Klein DJ, Bittner GD (2011) Most plastic products release estrogenic chemicals: a potential health problem that can be solved. Environmental Health Perspectives 119(7): 989-996.

33. Brandt-Rauf PW, Li Y, Long C, Monaco R, Kovvali G, et al. (2012) Plastics and carcinogenesis: The example of vinyl chloride. Journal of Carcinogenesis 11: 5 .

34. Ludovic H, Alexandre D, Ika PP, Camille L, Ronan J, et al. (2017) Occurrence and effects of plastic additives on marine environments and organisms: A review. Chemosphere 182: 781-793.

35. Rao BM (2019) Microplastics in the aquatic environment: implications for post-harvest fish quality. Indian Journal of Fisheries 66(1): 142152.

\section{Your next submission with Juniper Publishers will reach you the below assets}

